\title{
Unit Root Tests are Useful for Selecting Forecasting Models
}

\author{
Francis X. Diebold \\ Department of Economics \\ University of Pennsylvania
}

\author{
Lutz Kilian
}

Department of Economics

University of Michigan

First Draft: July 1997

This Draft/Print: January 18, 1999

Copyright 8 1997-1999 F.X. Diebold and L. Kilian. This paper is available on the World Wide Web at http://www.ssc.upenn.edu/ diebold/ and may be freely reproduced for educational and research purposes, so long as it is not altered, this copyright notice is reproduced with it, and it is not sold for profit.

Correspondence to:

F.X. Diebold

Department of Economics

University of Pennsylvania

3718 Locust Walk

Philadelphia, PA 19104

fdiebold@mail.sas.upenn.edu

Abstract: We study the usefulness of unit root tests as diagnostic tools for selecting forecasting models. Difference stationary and trend stationary models of economic and financial time series often imply very different predictions, so deciding which model to use is tremendously important for applied forecasters. Forecasters face three choices: always difference the data, never difference, or use a unit-root pretest. We characterize the predictive loss of these strategies for the canonical AR(1) process with trend, focusing on the effects of sample size, forecast horizon, and degree of persistence. We show that pretesting routinely improves forecast accuracy relative to forecasts from models in differences, and we give conditions under which pretesting is likely to improve forecast accuracy relative to forecasts from models in levels.

Acknowledgments: For helpful comments we thank participants at the June 1998 North American meeting of the Econometric Society, Montreal, and the December 1998 EC $^{2}$ meeting, Stockholm. Special thanks go to David Hendry, Phil Howrey, Paul Newbold, Allan Timmermann, and Tim Vogelsang. The National Science Foundation provided research support. 


\section{Motivation}

Difference stationary and trend stationary models of the same time series may imply very different predictions (e.g., Diebold and Senhadji, 1996). Deciding which model to use is therefore tremendously important for applied forecasters. Rather than employing one or the other model by default, one may use a unit root test as a diagnostic tool to guide the decision. In fact, one of the early motivations for unit root tests was precisely to help determine whether to use forecasting models in differences or levels in particular applications (e.g., Dickey, Bell, and Miller, 1986). Much of the recent econometric unit root literature has focused on the inability of unit root tests to distinguish in finite samples the unit root null from nearby stationary alternatives (e.g., Christiano and Eichenbaum, 1990; Rudebusch, 1993). But low power against nearby alternatives, which are typically the relevant alternatives in econometrics, is not necessarily a concern for forecasting. It has long been asserted, for example, that the accuracy of forecasts may be improved by employing a model in differences rather than a model in levels, if the root of the process is close to but less than unity (e.g., Box and Jenkins, 1976, p. 192). Ultimately, the question of interest for forecasting is not whether unit root pretests select the "true" model, but rather whether they select models that produce superior forecasts. Surprisingly little is known about the efficacy of unit root tests for this purpose.

The comparative merits of strategies such as "always difference," "never difference," or "sometimes difference, according to the results of a unit root pretest" will in general depend on the degree of persistence of the true process, the forecast horizon of interest, the sample size, and the properties of the pretest. Hence the purpose of this paper is to explore systematically the extent to which pre-testing for unit roots affects forecast accuracy for a variety of degrees of 
persistence, forecast horizons and sample sizes.

We focus on the univariate trending autoregressive case with high persistence, which is of particular interest in economics and finance. Because exact finite-sample analytics appear out of the question for the trending dynamic model of interest, we proceed by Monte Carlo simulation as described in section 2 . The results are sharp and intuitive, and are powerfully summarized by compact response surfaces in section 3. In section 4, we meld the results into practical prescriptions for applied work. Finally, we offer concluding remarks and directions for future research in section 5 .

\section{Experimental Design}

Here, as always, there is inescapable tension in experimental design. On the one hand, we want to examine a wide enough range of data-generating processes (DGPs) such that the results shed light on the behavior of alternative methods and on a range of empirically-relevant situations. Clearly, we will want to examine a range of forecast horizons, degrees of persistence, and sample sizes. On the other hand, it is crucial that the DGPs examined be simple and their range small enough to promote manageable and interpretable Monte Carlo analysis.

Use of a first-order autoregressive DGP, with differing degrees of persistence corresponding to different autoregressive parameter values, represents an appealing compromise. If, however, the analysis is to provide meaningful recommendations for applied work, we view the inclusion of a time trend as crucial. Trending behavior is routinely present in economic and financial series and increases the amount of bias in the least squares estimator of autoregressive parameters, which has important implications for the performance of the alternative strategies of "always differencing," "never differencing," or "pretesting". 
Hence we examine a trending $\mathrm{AR}(1)$ process of the form

$$
\begin{gathered}
\left(\mathrm{y}_{\mathrm{t}}-\mathrm{a}-\mathrm{bt}\right)=\rho\left(\mathrm{y}_{\mathrm{t}-1}-\mathrm{a}-\mathrm{b}(\mathrm{t}-1)\right)+\varepsilon_{\mathrm{t}} \\
\quad \text { iid } \\
\varepsilon_{\mathrm{t}} \sim \mathrm{N}\left(0, \sigma^{2}\right),
\end{gathered}
$$

$\mathrm{t}=1,2, \ldots, \mathrm{T}$. We can rewrite the process as

$$
\mathrm{y}_{\mathrm{t}}=\mathrm{k}_{1}+\mathrm{k}_{2} \mathrm{t}+\rho \mathrm{y}_{\mathrm{t}-1}+\varepsilon_{\mathrm{t}}
$$

where

$$
\mathrm{k}_{1}=\mathrm{a}(1-\rho)+\rho b
$$

and

$$
\mathrm{k}_{2}=\mathrm{b}(1-\rho)
$$

Perhaps more intuitively, we can express the process in components form as the sum of a linear trend and an $\mathrm{AR}(1)$ process,

$$
\mathrm{y}_{\mathrm{t}}=\mathrm{T}_{\mathrm{t}}+\mathrm{x}_{\mathrm{t}}
$$

where

$$
\mathrm{T}_{\mathrm{t}}=\mathrm{a}+\mathrm{bt}
$$


and

$$
\mathrm{x}_{\mathrm{t}}=\rho \mathrm{x}_{\mathrm{t}-1}+\varepsilon_{\mathrm{t}}
$$

When $\rho=1$ the process is a random walk with drift b, and when $\rho<1$ the process is covariance stationary $\mathrm{AR}(1)$ deviations from a linear trend with slope $\mathrm{b}$.

We parameterize the process to be consistent with U.S. postwar quarterly real GNP data by setting $\mathrm{a}=7.3707, \mathrm{~b}=0.0065$, and $\sigma=0.0099$. This parameterization is likely to be representative for many other trending macroeconomic time series as well. We examine $\rho \in\{0.5,0.9,0.97,0.99,1\}$ and $\mathrm{T} \in\{25,30: 10: 80,100: 20: 180,200: 40: 1000\}$, which includes relevant degrees of persistence and sample sizes for annual, quarterly, monthly, weekly, and daily data.

We compare the performance of three forecasting models: AR(1) in levels with linear deterministic trend (L, for "levels"), random walk with drift (D, for "differences"), and the model suggested by Dickey-Fuller unit root pre-tests using 5 percent finite-sample critical values (P, for "pretest"). For all models, the estimation method is ordinary least squares (OLS). The common objective is to forecast the level of the series at horizons, $h$, ranging from 1 to 100 periods ahead. Using common random numbers across models, we evaluate the performance of each model by its unconditional prediction mean squared error (PMSE) in 20,000 Monte Carlo trials. For each value of $\rho$, we calculate the ratios $\operatorname{PMSE}(\mathrm{D}) / \mathrm{PMSE}(\mathrm{L}), \operatorname{PMSE}(\mathrm{D}) / \mathrm{PMSE}(\mathrm{P})$, and PMSE(P)/PMSE(L) for all combinations of $h$ and $T$.

\section{Results}

In Figures 1-3 we show, for various values of $\rho$, response surfaces for 
PMSE(D)/PMSE(L), PMSE(D)/PMSE(P), and PMSE(P)/PMSE(L), for all combinations of forecast horizon (h) and sample size (T). In particular, for each value of $\rho$, we show the relative PMSE as a function of $\mathrm{h}$ and T. We present unsmoothed response surfaces, because they are quite smooth already and readily interpretable without additional smoothing.

$\underline{\text { D vs. } L}$

Figure 1 makes clear that neither D nor L dominates always; the relative forecast accuracy in general depends on $\rho, \mathrm{h}$ and $\mathrm{T}$. Not surprisingly, for $\rho=1$ the $\mathrm{D}$ model is uniformly more accurate than the $\mathrm{L}$ model, because in that case $\mathrm{D}$ is the true model. The ratio PMSE(D)/PMSE(L) drops toward 0 as the forecast horizon $h$ grows (for fixed sample size, $T$ ). This happens because the distortions resulting from the Dickey-Fuller small-sample bias, which plague the $\mathrm{L}$ model, are magnified as $\mathrm{h}$ grows. This effect, of course, is most pronounced for smaller sample sizes, for which the Dickey-Fuller bias is greatest. As a result, for fixed forecast horizon $\mathrm{h}$, the ratio PMSE(D)/PMSE(L) drops toward 0 as $\mathrm{T}$ declines.

In contrast, for roots smaller than unity, $\mathrm{D}$ is false and would not be expected to dominate $\mathrm{L}$ always. That expectation is confirmed. For $\rho=0.99$, for example, for sample sizes in excess of 600 , forecasts from $\mathrm{L}$ are marginally more accurate than those from $\mathrm{D}$. The $\mathrm{D}$ model forecast is least accurate for large $\mathrm{h}$. This is to be expected, as the error resulting from the false imposition of a unit root is compounded with rising $\mathrm{h}$. In contrast, small-sample bias is of little concern for such large samples, and L is quite accurate. Nevertheless, for smaller sample sizes, forecasts from D continue to be more accurate than forecasts on the basis of the biased estimator associated with L, especially for long forecast horizons.

The tradeoffs between the use of $\mathrm{D}$ and $\mathrm{L}$ become more pronounced as the persistence of 
the process declines. For $\rho=0.97$, the ratio $\operatorname{PMSE}(\mathrm{D}) / \mathrm{PMSE}(\mathrm{L})$ exceeds 1 over much of the parameter space and is highest when both $\mathrm{T}$ and $\mathrm{h}$ are large. For small $\mathrm{T}$ and large $\mathrm{h}$, however, the ratio still tends to approach zero. The poor relative performance of the $\mathrm{L}$ model for small $\mathrm{T}$ and large $\mathrm{h}$ is not only due to small-sample bias. In addition, the PMSE of $\mathrm{L}$ is inflated by occasional explosive estimates, resulting in absurd forecasts, especially at long forecast horizons. ${ }^{1}$ In contrast, the constraint implicit in D renders its forecasts more consistently reasonable, even when $\mathrm{D}$ is incorrect.

We also find that for small $\mathrm{T}$, the ratio $\mathrm{PMSE}(\mathrm{D}) / \mathrm{PMSE}(\mathrm{L})$ decreases in $\mathrm{h}$, whereas for large $\mathrm{T}$ it increases in $\mathrm{h}$. This reversal makes sense. For small $\mathrm{T}$, the loss in forecast accuracy from poor estimates of $\mathrm{L}$ is much greater than the loss from inappropriately using the model in differences, and the tradeoff worsens as $\mathrm{h}$ increases. In contrast, for large $\mathrm{T}$, the forecast from $\mathrm{L}$ is increasingly more accurate (because the least squares estimator is consistent), whereas using the model in differences (and thereby imposing a unit root) introduces a systematic distortion in forecasting, the effects of which are amplified with $h$.

${ }^{1}$ The problem is that for processes with large roots there is a non-negligible probability in small samples of drawing an explosive estimate. As a result, using L, we occasionally encounter predictions based on "outlier" explosive models, which have extremely large prediction errors and dominate the PMSE. Typically in such cases the forecast dives toward minus infinity, due to a slightly negative estimated trend coefficient and an estimated root in excess of unity. As a result, the PMSE does not improve at long horizons as the process reverts back to its mean, as one might have expected, because the effect of explosive forecasts on the PMSE obviously worsens for longer horizons. The problem does not arise in $\mathrm{D}$ because of the imposition of a unit root. While the PMSE of D worsens for longer forecast horizons, as one would expect, the extent to which its PMSE deteriorates is dwarfed by the PMSE of $\mathrm{L}$, which is inflated by the occasional explosive outliers. The net result is a ratio of PMSE(D)/PMSE(L) that approaches zero. In light of these phenomena, we also experimented with a mixed strategy (M), in which we used the $L$ forecast unless the $\mathrm{L}$ forecast was explosive, in which case we replaced the $\mathrm{L}$ forecast with the $\mathrm{D}$ forecast. As expected, the small-sample forecast accuracy of $\mathrm{M}$ was much better than that of $\mathrm{L}$, but, interestingly, the modification did not affect our qualitative results. 
The results for $\rho=0.9$ are similar, but even more pronounced. Differencing continues to improve forecast accuracy for small and moderate sample sizes, but as the persistence of the process declines, the gains are limited to increasingly smaller sample sizes. At the same time, for larger sample sizes, L becomes increasingly more accurate than the model in differences, especially as the forecast horizon increases.

It is interesting to note that in the case of $\rho=0.9$, as well as several cases discussed later, for large $\mathrm{T}$ the ratio $\mathrm{PMSE}(\mathrm{D}) / \mathrm{PMSE}(\mathrm{L})$ (and later PMSE(D)/PMSE(P)) approaches 2 as $\mathrm{h}$ grows. This phenomenon occurs when $\mathrm{T}$ is large enough so that the parameters of the $\mathrm{L}$ model are estimated precisely (or, equivalently, for $\mathrm{T}$ large enough so that the unit root null hypothesis tends to be rejected correctly, and the resulting trend stationary model is estimated precisely). The explanation is simple: in population, when $\rho<1$, the long-horizon forecast error from $L$ is approximately the unconditional variance of the process, $\operatorname{var}\left(\mathrm{y}_{\mathrm{t}}\right)$, whereas the long-horizon forecast error from the model in differences is approximately $\operatorname{var}\left(\mathrm{y}_{\mathrm{t}+\mathrm{h}}-\mathrm{y}_{\mathrm{t}}\right)$, which approximately equals twice the unconditional variance of the process. Appearance of these population results in the finite-sample Monte Carlo results requires a sample large enough to facilitate precise estimation and powerful unit root testing.

Finally, for $\rho=0.5$, the $\mathrm{L}$ model uniformly dominates the $\mathrm{D}$ model. What makes this case interesting is the emergence of a "ridge" in the response surface for small T. The height of the ridge steadily increases in $\mathrm{h}$. We do not yet have an explanation for the ridge.

Taken as a whole, the $\mathrm{D}$ vs. $\mathrm{L}$ results appear driven by the fact that differencing provides insurance against problems due to Dickey-Fuller bias and explosive root problems, at a cost. Those problems are most severe for small $\mathrm{T}$ and large $\mathrm{h}$, so the insurance is more than worth its 
cost. Elsewhere in the parameter space, however, the situation is reversed. As a rule of thumb, the results suggest that one is better off differencing if the sample size is small or moderate and the process appears highly persistent, and conversely. Note in particular that the "we don't know and we don't care" view is explicitly refuted: although the trend-stationary vs. difference stationary distinction is not important in some contexts; it most definitely makes a difference for forecasting. Moreover, the best forecasting model is not necessarily the true model; the ability of a unit root pretest to select a good forecasting model is distinct from its ability to select the true model. The fact that neither D nor L dominates uniformly suggests that unit root pretests may help to improve forecast accuracy. We now explore this possibility in detail.

$\underline{\text { D vs. } P}$

Figure 2 makes clear that the pre-testing strategy dominates that of routinely differencing the data for almost all sample sizes and forecast horizons. The reason is that our pretest takes the unit root hypothesis as its null. For alternatives close to the unit root null, the power of the pretest is low, so the pre-test model reduces to the model in differences. Hence, $\mathrm{P}$ performs much like D did in Figure 1, when that model is a good approximation. On the other hand, for processes with roots far from the unit root null, the Dickey-Fuller test is bound to find strong evidence against the null, in which case the pre-test model reduces to L, which we know to be much more accurate than $\mathrm{D}$ when persistence is low.

In particular, we find that for $\rho=1$, when $D$ is the true model, the pre-test is unlikely to reject the model in differences, resulting in a $\mathrm{PMSE}(\mathrm{D}) / \mathrm{PMSE}(\mathrm{P})$ ratio very close to 1 . Similar results hold for $\rho=0.99$. For $\rho=0.97$, P begins to exhibit important advantages over $\mathrm{D}$. For small $\mathrm{T}$, the test lacks power and rarely rejects, so $\mathrm{P}$ and $\mathrm{D}$ coincide, and PMSE(D)/PMSE(P) is 
effectively 1 regardless of $h$. As $T$ grows, the test rejects the unit root null more often, yet the ratio $\mathrm{PMSE}(\mathrm{D}) / \mathrm{PMSE}(\mathrm{P})$ remains close to 1 . The reason is that, at least for small $\mathrm{h}$, the PMSE for a highly persistent process in levels tends to be close to that of the equivalent model in differences. Because for large $\mathrm{T}$ the $\mathrm{L}$ model will be estimated rather precisely, the resulting forecast is about as accurate as that for the $\mathrm{D}$ model. In contrast, for both $\mathrm{T}$ and $\mathrm{h}$ large, the $\mathrm{P}$ forecast is considerably more accurate than the $\mathrm{D}$ forecast. This outcome is reflected in PMSE(D)/ PMSE(P) ratios in excess of 1. The reason is that for long horizons the false imposition of a unit root (which is of little consequence for short horizons) becomes a liability.

This tendency becomes even more apparent for $\rho=0.9$. Only for very small $\mathrm{T}$, the relative accuracy of $\mathrm{D}$ and $\mathrm{P}$ remains similar. In general, the $\mathrm{P}$ model is much more accurate than the $\mathrm{D}$ model. Finally, consider the process with $\rho=0.5$. In Figure 1 we showed that the loss in forecast accuracy from falsely adopting the model in differences is very high for $\rho=0.5$. However, the Dickey-Fuller pre-test has considerable power against this distant alternative and almost always rejects the model in differences. Hence, $\mathrm{P}$ and $\mathrm{L}$ tend to coincide, and the PMSE(D)/PMSE(P) results in Figure 2 are almost identical to those in the corresponding panel of Figure 1 for PMSE(D)/PMSE(L).

$\underline{\text { P vS. L }}$

In Figure 3 we directly compare $\mathrm{P}$ and L. For $\rho=1$, pre-testing gives similar results to differencing. Not surprisingly, pre-testing uniformly dominates the levels model. Similar results hold, at least for small and moderate sample sizes, for $\rho=0.99$. Figure 3 indicates that pre-test based forecasts are about as accurate as the level forecasts when $\rho=0.5$. The most interesting 
results are for the intermediate region of $\rho=0.97$ and $\rho=0.9$. For small and moderate $T$ and large h, Figure 3 shows evidence of a "ridge" on the response surface for $\rho=0.9$. That ridge flattens and widens for $\rho=0.97$, as the accuracy of the pre-test model improves. Evidently those are cases for which we would like to have rejected the unit root null hypothesis, but did not. Although the root is far enough from the unit circle, and the sample size (albeit small) is large enough for the levels models to be reasonably accurate, the Dickey-Fuller test is not powerful enough to detect the absence of a unit root. This observation suggests that more powerful unit

root tests such as the DF-GLS test of Elliott et al. (1996) could be used to flatten the ridge and to improve forecast accuracy. However, it is not obvious that more powerful tests would be beneficial in all regions of the parameter space. As we showed earlier, in some cases using incorrectly the model in differences rather than the correct model in levels will actually improve forecast accuracy, so more powerful unit root pre-tests may actually worsen forecast accuracy in those regions. More research is needed to quantify these tradeoffs.

\section{$\underline{\text { A Summary Assessment }}$}

Taken as a whole, the results cast the pretesting strategy in a favorable light. P dominates D uniformly, which makes clear that the Box-Jenkins strategy of routinely differencing to achieve stationarity is not to be recommended for constructing forecasting models. P does not dominate L uniformly, but it nevertheless dominates over much of the design space, which similarly casts doubt on a strategy relying on asymptotics by routinely specifying forecasting models in levels.

\section{Some Practical Advice}

Given the wide range of sample sizes and forecast horizons, it is difficult to translate the results in Figures 1-3 into concrete practical advice. Moreover, the DGP based on quarterly real 
GNP may not be representative for other frequencies. We therefore repeated the simulation exercise for selected sample sizes and forecast horizons for DGPs specifically chosen to be representative for each frequency. As the pre-testing strategy clearly dominates differencing, we focus on the choice between pre-testing and routinely forecasting on the basis of the level model.

Table 1 summarizes the simulation design for each frequency. The quarterly DGP based on U.S. real GNP is identical to the DGP defined in section 2. The annual DGP is based on 125 observations for U.S. per capita real GNP as defined in Diebold and Senhadji (1996). The daily DGP is based on the Dow Jones stock price index for 1/1/74-4/2/98, and the monthly DGP is based on U.S. industrial production index (DRI code: IP) for the post-war period.

For annual data (say, $\mathrm{T}=40-160$ and $\mathrm{h}=1-100$ ), we find that pre-testing unambiguously improves forecast accuracy for all forecast horizons and sample sizes if the root of the DGP is 0.97 or higher. For $\rho=0.9$, pre-testing still improves forecast accuracy for sample sizes as high as 70 , but does not perform as well as the $\mathrm{L}$ model in larger samples. For $\rho=0.5$, the two models are tied. In practice, this result suggests using pre-tests for data sets of up to 70 annual observations, and for all larger sample sizes, provided the process is likely to be highly persistent. In the remaining cases, the $\mathrm{L}$ model is preferred.

For quarterly data (say, $\mathrm{T}=80-200$ and $\mathrm{h}=1-16$ ), the $\mathrm{P}$ model is more accurate for all forecast horizons and sample sizes, provided the root of the process is 0.97 or higher. For $\rho=0.9$, the level model is uniformly more accurate, and for $\rho=0.5$ the models are tied. We conclude that pre-testing should be used for all processes with roots of 0.97 or higher, and the $\mathrm{L}$ model for processes with smaller roots.

For monthly data (say, $\mathrm{T}=240-480$ and $\mathrm{h}=1-48$ ), pre-testing improves forecast accuracy 
for $\rho=1$ and for $\rho=0.99$ for all forecast horizons and sample sizes considered. For $\rho=0.97$ and $\rho=0.9$, however, the $\mathrm{L}$ model is at least as accurate as the P model, and for $\rho=0.5$ the two methods are tied. This finding suggests that pre-testing is useful only for processes with roots of 0.99 or higher, and in all other cases the L model will be more accurate.

For daily data (say, $\mathrm{T}=360-720$ and $\mathrm{h}=1-90$ ), pre-testing only improves forecast accuracy uniformly for $\rho=1$. For $\rho=0.99$ the performance is mixed, with the P model being more accurate for sample sizes of fewer than 600 days at all horizons. For larger sample sizes, the $\mathrm{L}$ model is slightly more accurate at long forecast horizons, and roughly as accurate as the $\mathrm{P}$ model at shorter horizons. For $\rho=0.97$ the $\mathrm{L}$ model is uniformly more accurate. For $\rho=0.9$ the L model is slightly more accurate for small $\mathrm{T}$, especially for $\mathrm{T}<500$, except at very short horizons. For larger sample sizes the differences vanish. For $\rho=0.5$ the two methods are tied. This finding suggests that pre-testing is useful for forecasting daily data only if the data are very persistent with roots of 0.99 or higher. For other applications, the L model is likely to be more appropriate.

Our advice may appear to be circular in that it often depends on knowledge of the true root. In practice, however, OLS point estimates of the roots for quarterly macroeconomic data are typically in excess of 0.97 , estimates for monthly data are in excess of 0.99 and estimates for daily data are well in excess of $0.99 .{ }^{2}$ Moreover, the presence of small-sample bias suggests that these OLS estimates, if anything, understate the true roots. We therefore conclude that pre-

${ }^{2}$ These differences in dominant roots across sampling frequencies make sense when viewed in terms of the implied half-life of the response to an innovation (see Caner and Kilian, 1998). 
testing is recommended for virtually all forecasting exercises involving trending macroeconomic data.

\section{Concluding Remarks and Directions for Future Research}

Difference stationary and trend stationary models of the same series may imply very different predictions. Deciding which model to use thus is tremendously important for applied forecasters, and unit root pre-tests may provide a formal criterion for deciding whether to difference the data. However, very little is known about the usefulness of unit root tests as diagnostic tools for selecting a forecasting model. In an effort to remedy this situation, we conducted a Monte Carlo study in which we explored systematically the extent to which pretesting for unit roots improves forecast accuracy in a canonical AR(1) model with trend, for a variety of sample sizes, forecast horizons, and degrees of persistence. We found strong evidence that pre-testing improves forecast accuracy relative to routinely differencing the data. We also characterized in detail under what conditions pre-testing is likely to improve forecast accuracy relative to forecasts from models in levels and provided some practical advice.

Our work builds on, and complements, a small literature dating back almost a decade. Stock (1990) finds in a particular application that model specification in levels vs. differences matters little, but points out that in general it will. Some preliminary evidence in favor of pretesting is presented in Campbell and Perron (1991) who study 1-step-ahead and 20-step-ahead forecasts made using autoregressive models. They show that one loses little by pretesting relative to using the true model, and sometimes one actually gains. In their study, autoregressive models in levels do best for series that are near white noise, while autoregressive models in differences do best for series that are near a random walk. Cochrane (1991), in a comment on Campbell and 
Perron, explores longer forecast horizons. He compares level and difference stationary models, but does not discuss pre-testing. Neither do Franses and Kleibergen (1996), who study the outof-sample forecasting accuracy of trend stationary and difference stationary models for the Nelson-Plosser data set.

The extant work most closely related to ours is Stock (1996) and Stock and Watson (1998). Stock (1996) provides theoretical arguments in favor of pre-testing from a local-to-unity asymptotic perspective and presents some Monte Carlo evidence for the AR(1) model without trend. In recent contemporaneous and independent work, Stock and Watson (1998) provide a comprehensive empirical study of the out-of-sample accuracy of macroeconomic forecasting models; one of their conclusions is that autoregressive models based on unit root pre-tests tend to perform well.

Our Monte Carlo results complement and strengthen both the largely theoretical work of Stock (1996) and the purely empirical work of Stock and Watson (1998). Our analysis is closer in spirit to Stock's, but there are important differences. Stock focused narrowly on documenting problems in long horizon forecasting from models with roots close to unity. Moreover, he did not consider models with trend, and he fixed the ratio $\mathrm{h} / \mathrm{T}$ in his Monte Carlo analysis. Our analysis, in contrast, is wider in scope. It includes a grid of alternative values of $\rho, \mathrm{h}$ and $\mathrm{T}$, corresponding to applications of autoregressive forecast models using daily, weekly, monthly, quarterly, and annual data. To the extent that results can be compared directly, ours and Stock's tend to agree; however, we find stronger evidence in favor of pre-testing than Stock (1996), reflecting the greater importance of small-sample bias in models with trends.

There are many useful directions for future research. Given the narrow confines of our 
$\mathrm{AR}(1)$ data generating process, the results by necessity are tentative, and there are many obvious but nevertheless important variations on the applications considered in this paper. For example, we chose to focus on just one of many pre-tests for unit roots, and we ignored asymptotic refinements of unit root tests based on bootstrap theory (e.g., Nankervis and Savin, 1996). Moreover, Stock (1996) showed that the asymptotically more powerful DF-GLS test of Elliott et al. (1996) may further improve forecast accuracy. Our analysis confirmed that there are important potential advantages to the use of more powerful unit root tests in some regions of the parameter space, but it also showed that low power in some cases may improve forecast accuracy. This finding suggests that there are likely to be tradeoffs between different unit root pre-tests in terms of their power properties. Working with daily data, for example, may call for different unit root tests than working with annual data. Future research will have to quantify these tradeoffs. ${ }^{3}$

Another limitation of our Monte Carlo analysis is the greatly simplified lag structure of the data generating process. Further research is required to verify the robustness of our findings in models with richer dynamics. We also deliberately ignored the issue of lag order uncertainty at this stage of the analysis. Future work will have to address the fact that the population model is unknown in practice and may not even be of finite lag order. Appropriate data-based lag order selection procedures for the class of $\operatorname{ARMA}(p, q)$ models are discussed for example in $\mathrm{Ng}$ and Perron (1995).

${ }^{3}$ In addition, it would be of interest to explore tests that take $\mathrm{L}$ rather than $\mathrm{D}$ as the null hypothesis (see Kwiatkowski, Phillips, Schmidt and Shin, 1992, and Leybourne and McCabe, 994). Pretest procedures based on such unit root tests might be expected to dominate L for the same reason that the Dickey-Fuller pretest dominates D. This optimism is tempered, however, by recent work of Caner and Kilian (1998), which documents large finite-sample size distortions of such tests and the impossibility of fixing them by conventional means. 
A third limitation of our analysis is our focus on univariate models. Univariate models are of central interest in many applications and often have proved superior to multivariate forecasting models, but they are not the only model in use. For example, Stock $(1990,1994)$ notes that results for univariate models do not bear directly on macroeconomic forecasting, which is typically multivariate. Future research undoubtedly will have to include vector valued processes. While the standard ADF test used in this paper is widely used as a pre-test for vector autoregressions, a similar analysis for multivariate cointegration tests would be useful. One would conjecture that imposing cointegration in small samples ought to improve forecast accuracy, whether or not cointegration holds exactly. However, there is reason to believe that imposing cointegration may be less important than commonly thought. For example, Christoffersen and Diebold (1998) show that when forecasting cointegrated systems at long horizons, imposing the correct order of integration is crucial, but imposing cointegration is not.

A fourth extension would be to allow for endogenously selected deterministic trend breaks under the alternative. In particular, piece-wise linear deterministic trend models may forecast more accurately than linear models. The ADF test considered in this paper does not allow for trend breaks, but tests like those developed in Zivot and Andrews (1992) do. Moreover, alternative procedures for the simultaneous determination of the trend model and of the order of integration have been proposed for example by Phillips and Ploberger (1994).

A fifth extension would be to explore alternative estimators. Canjels and Watson (1997) document that for processes with roots close to unity, the feasible GLS estimator of Prais and Winsten (1954) provides the best estimates of the trend coefficient. Given the obvious importance of accurate trend estimates, especially at long forecast horizons, a comparison of the 
forecast accuracy of the Prais-Winston estimator to the OLS estimator used in this paper would be useful. In addition, it would be worthwhile to study bias-corrected OLS forecasts. Our simulation results are consistent with the view that much of the advantage of falsely imposing a unit root in borderline stationary processes is due to the elimination of OLS small-sample bias. A natural conjecture is that the mean squared error of forecasts from trend stationary models may be improved by replacing the OLS autoregressive coefficient estimates by bias-corrected coefficient estimates. Such corrections have been used successfully in the closely related area of impulse response analysis. For example, Andrews and Chen (1994) report that approximate median bias corrections for univariate autoregressive models may reduce the mean squared error of impulse response estimates for at least some parameter ranges and horizons. Alternative bias corrections based on the mean bias of the autoregressive coefficient estimates have been explored by Rudebusch (1993) and Kilian (1998) based on work by Shaman and Stine (1988) and Pope (1990).

A sixth extension would be to examine the robustness of the results to structural change, in light of recent work by Clements and Hendry (1998) indicating that certain specifications may be relatively more robust to structural change than others.

A final extension, and perhaps the most novel and interesting in our view, would be to consider unit root test sizes other than 5 percent, and to determine how the performance of $\mathrm{P}$ relative to $\mathrm{D}$ and $\mathrm{L}$ varies with test size. In particular, it should be possible to tune the test size to optimize the performance of $\mathrm{P}$. The present fairly stringent size of 5 percent leads to domination of $\mathrm{D}$ by $\mathrm{P}$, because the pretest selects $\mathrm{D}$ except when there is strong evidence against $\mathrm{D}$, but fails to produce domination of $\mathrm{L}$ by $\mathrm{P}$. It is possible that increasing the test size would leave largely 
intact the domination of $\mathrm{D}$ by $\mathrm{P}$, but could bring us closer to a similar domination of $\mathrm{L}$ by $\mathrm{P}$. At any rate, there is certainly no reason to think that the arbitrary size of 5 percent is necessarily close to optimal. Hence our results on the generally good performance of the pretesting strategy are conservative -- some simple additional tuning could cast the pretest strategy in an even more favorable light. 


\section{References}

Andrews, D.W.K. and Chen, H.-Y. (1994), "Approximately Median-Unbiased Estimation of Autoregressive Models," Journal of Business and Economic Statistics, 12, 187-204.

Box, G.E.P. and Jenkins, G.W. (1976), Time Series Analysis, Forecasting and Control, Second Edition. Oakland, CA: Holden-Day.

Campbell, J.Y. and Perron, P. (1991), "Pitfalls and Opportunities: What Macroeconomists Should Know About Unit Roots," in O. Blanchard and S. Fischer (eds.), NBER Macroeconomics Annual, 1991. Cambridge, Mass.: MIT Press.

Caner, M. and Kilian, L. (1998), "Size Distortions of Tests of the Null Hypothesis of Stationarity: Evidence and Implications for Applied Work," Manuscript, Department of Economics, University of Michigan.

Canjels, E. and Watson, M. (1997), "Estimating Deterministic Trends in the Presence of Serially Correlated Errors," Review of Economics and Statistics, 79, 184-200.

Christiano, L.J. and Eichenbaum, M. (1990), "Unit Roots in Real GNP: Do we Know and do we Care?," Carnegie-Rochester Conference Series on Public Policy, 32, 7-82.

Christoffersen, P.F. and Diebold, F.X. (1998), "Cointegration and Long-Horizon Forecasting," Journal of Business and Economic Statistics, 16, 450-458.

Clements, M.P. and Hendry, D.F. (1998), "How to win Forecasting Competitions in Economics," Manuscript, Economics Department, Warwick University, and Nuffield College, Oxford.

Cochrane, J.H. (1991), “A Comment on Campbell and Perron," in O. Blanchard and S. Fischer (eds.), NBER Macroeconomics Annual, 1991. Cambridge, Mass.: MIT Press.

Dickey, A.D., Bell, W.R. and Miller, R.B. (1986), "Unit Roots in Time Series Models: Tests and Implications," The American Statistician, 40, 12-26.

Diebold, F.X. and Senhadji, A.S. (1996), "The Uncertain Unit Root in Real GNP: Comment," American Economic Review, 86, 1291-1298.

Elliott, G., Rothenberg, T.J., and Stock, J.H. (1996), "Efficient Tests for an Autoregressive Unit Root," Econometrica, 64, 813-836.

Franses, P.H. and Kleibergen, F. (1996), "Unit Roots in the Nelson-Plosser Data: Do They Matter for Forecasting?," International Journal of Forecasting, 12, 283-288. 
Kilian, L. (1998), “Small-Sample Confidence Intervals for Impulse Response Functions," Review of Economics and Statistics, 80, 218-230.

Kwiatkowski, D., Phillips, P.C.B., Schmidt, P., and Shin, Y. (1992), “Testing the Null Hypothesis of Stationarity Against the Alternative of a Unit Root," Journal of Econometrics, 54, 159178.

Leybourne, S.J. and McCabe, B.P.M. (1994), “A Consistent Test for a Unit Root,” Journal of Business and Economic Statistics, 12, 157-166.

Nankervis, J.C. and Savin, N.E. (1996), "The Level and Power of the Bootstrap t Test in the AR(1) Model with Time Trend," Journal of Business and Economic Statistics, 14, 161168.

Ng, S. and Perron, P. (1995), "Unit Root Tests in ARMA Models with Data Dependent Methods for the Selection of the Truncation Lag," Journal of the American Statistical Association, 90, 268-281.

Phillips, P.C.B. and Ploberger, W. (1994), "Posterior Odds Testing for a Unit Root with DataBased Model Selection," Econometric Theory, 10, 774-808.

Prais, S.J., and Winsten, C.B. (1954), “Trend Estimators and Serial Correlation,” Cowles Foundation Discussion Paper No. 383.

Pope, A.L. (1990), "Biases of Estimators in Multivariate Non-Gaussian Autoregressions," Journal of Time Series Analysis, 11, 249-258.

Rudebusch, G.D. (1993), “The Uncertain Unit Root in Real GNP," American Economic Review, 83, 264-272.

Shaman, P. and Stine, R.A. (1988), "The Bias of Autoregressive Coefficient Estimators," Journal of the American Statistical Association, 83, 842-848.

Stock, J.H. (1990), "Unit Roots in Economic Time Series: Do We Know and Do We Care? A Comment," Carnegie-Rochester Conference Series on Public Policy, 32, 63-82.

Stock, J.H. (1994), "Unit Roots, Structural Breaks, and Trends," in R. Engle and D. McFadden (eds.), Handbook of Econometrics, Volume 4. Amsterdam: North-Holland.

Stock, J.H. (1996), "VAR, Error Correction, and Pretest Forecasts at Long Horizons," Oxford Bulletin of Economics and Statistics, 58, 685-701.

Stock, J.H. and Watson, M.W. (1998), “A Comparison of Linear and Nonlinear Univariate 
Models for Forecasting Macroeconomic Time Series," Manuscript, Kennedy School, Harvard University, and Woodrow Wilson School, Princeton University.

Zivot, E. and Andrews, D.W.K. (1992), "Further Evidence on the Great Crash, the Oil Price Shock, and the Unit Root Hypothesis," Journal of Business and Economic Statistics, 10, 251-270. 
Table 1

Data Generating Processes

\begin{tabular}{|l|c|c|c|l|}
\hline Frequency & $\mathrm{a}$ & $\mathrm{b}$ & $\sigma$ & DGP based on: \\
\hline Annual & -6.0674 & 0.0173 & 0.0500 & $\begin{array}{l}\text { U.S. per capita } \\
\text { real GNP }\end{array}$ \\
\hline Quarterly & 7.3707 & 0.0065 & 0.0099 & U.S. real GNP \\
\hline Monthly & 3.3654 & 0.0024 & 0.0105 & $\begin{array}{l}\text { U.S. industrial } \\
\text { production }\end{array}$ \\
\hline Daily & 5.1126 & 0.0004 & 0.0095 & $\begin{array}{l}\text { Dow Jones } \\
\text { stock price index }\end{array}$ \\
\hline
\end{tabular}

Notes: The DGP is $\left(\mathrm{y}_{\mathrm{t}}-\mathrm{a}-\mathrm{bt}\right)=\rho\left(\mathrm{y}_{\mathrm{t}-1}-\mathrm{a}-\mathrm{b}(\mathrm{t}-1)\right)+\varepsilon_{\mathrm{t}}$, where $\sigma$ is the standard error of $\varepsilon_{\mathrm{t}}$. 


\section{Figure 1a: PMSE(D)/PMSE(L)}

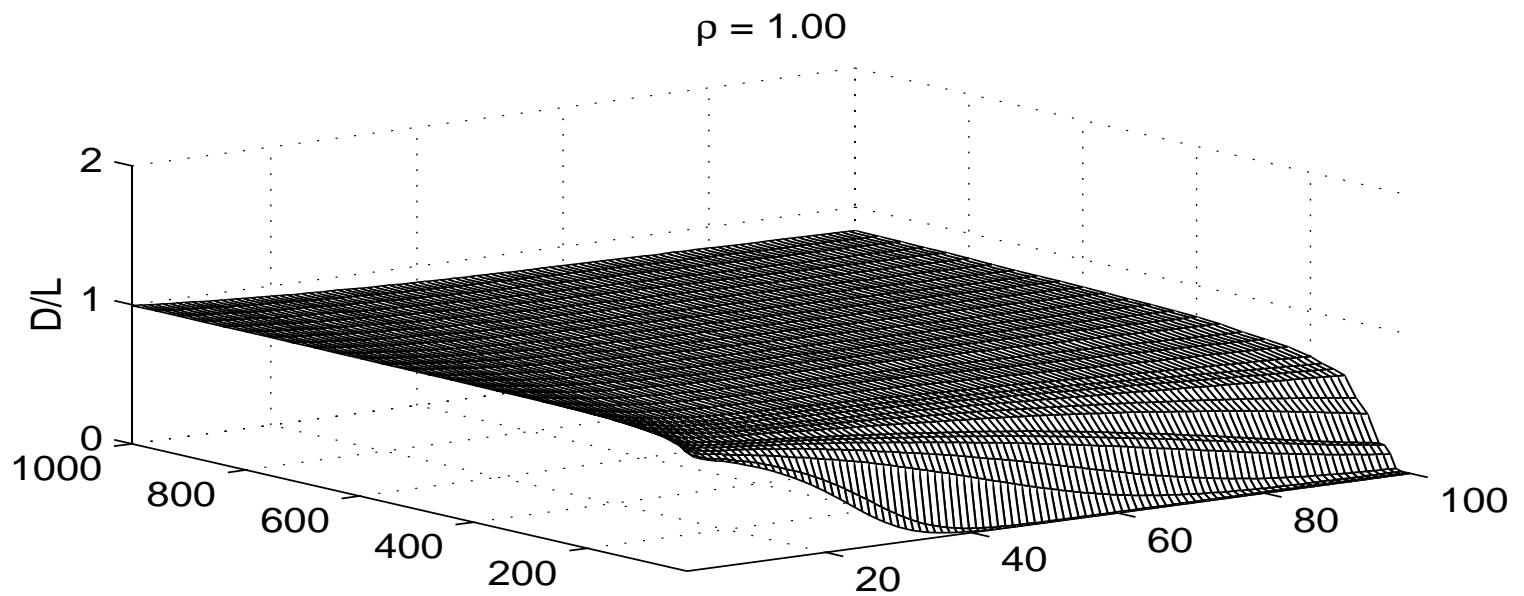

Sample Size

Forecast Horizon

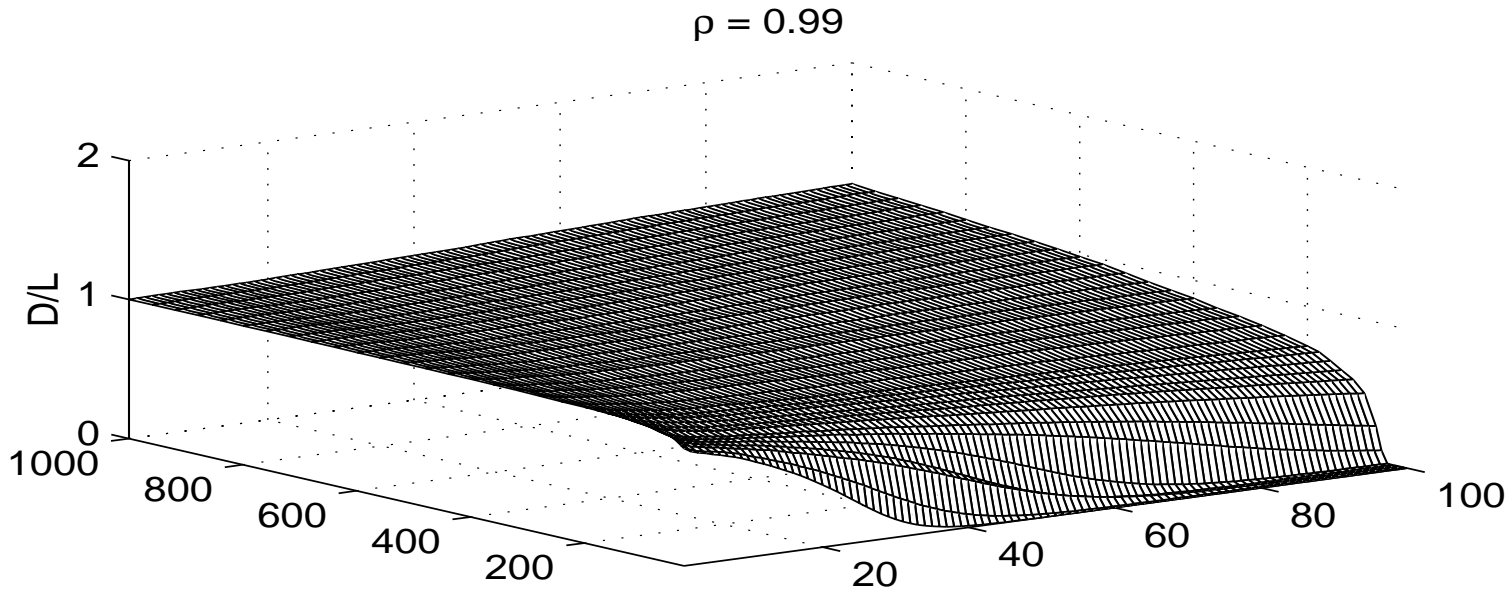

Sample Size

Forecast Horizon

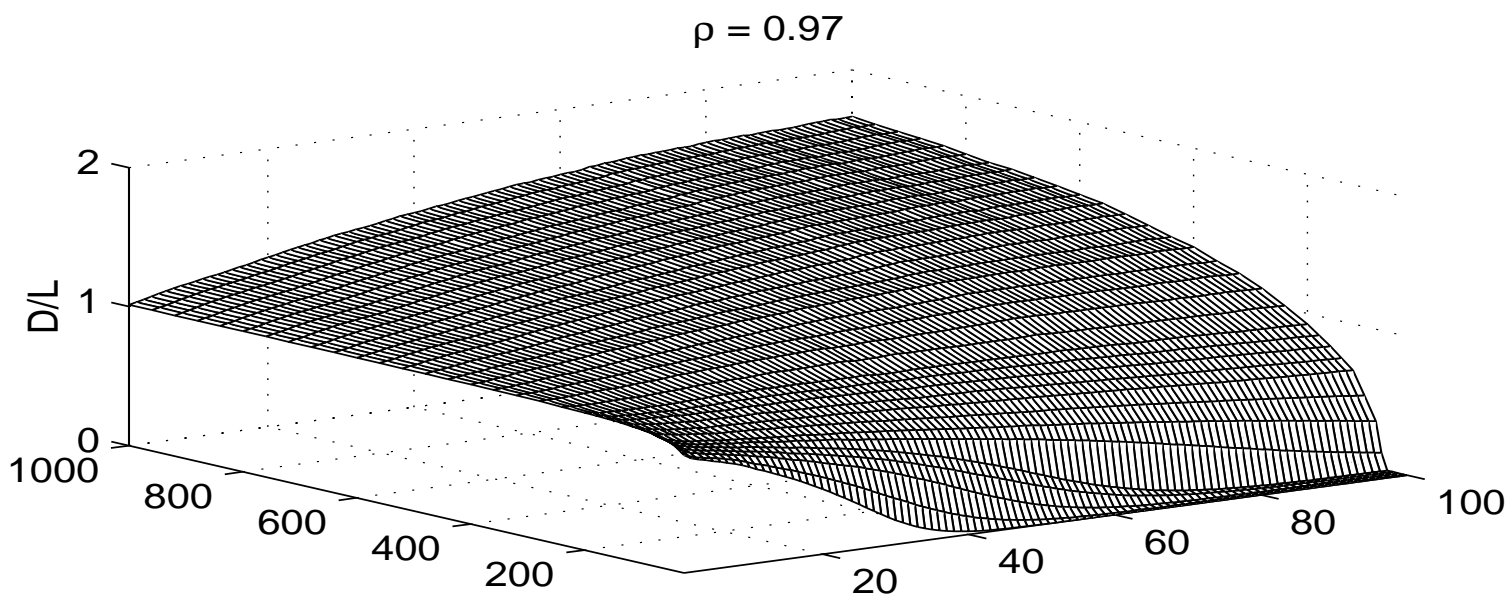

Sample Size

Forecast Horizon

SOURCE: 20,000 Monte Carlo trials based on DGP $y_{t}=(a-a \rho+b \rho)+(b-b \rho) t+\rho y_{t-1}+\varepsilon_{t}$, where $\varepsilon_{t} \sim N\left(0,0.01^{2}\right), a=7.3707, b=0.0065$.

$\mathrm{D}$ denotes the model in first differences; $\mathrm{L}$ denotes the model in levels. 


\section{Figure 1b: PMSE(D)/PMSE(L)}

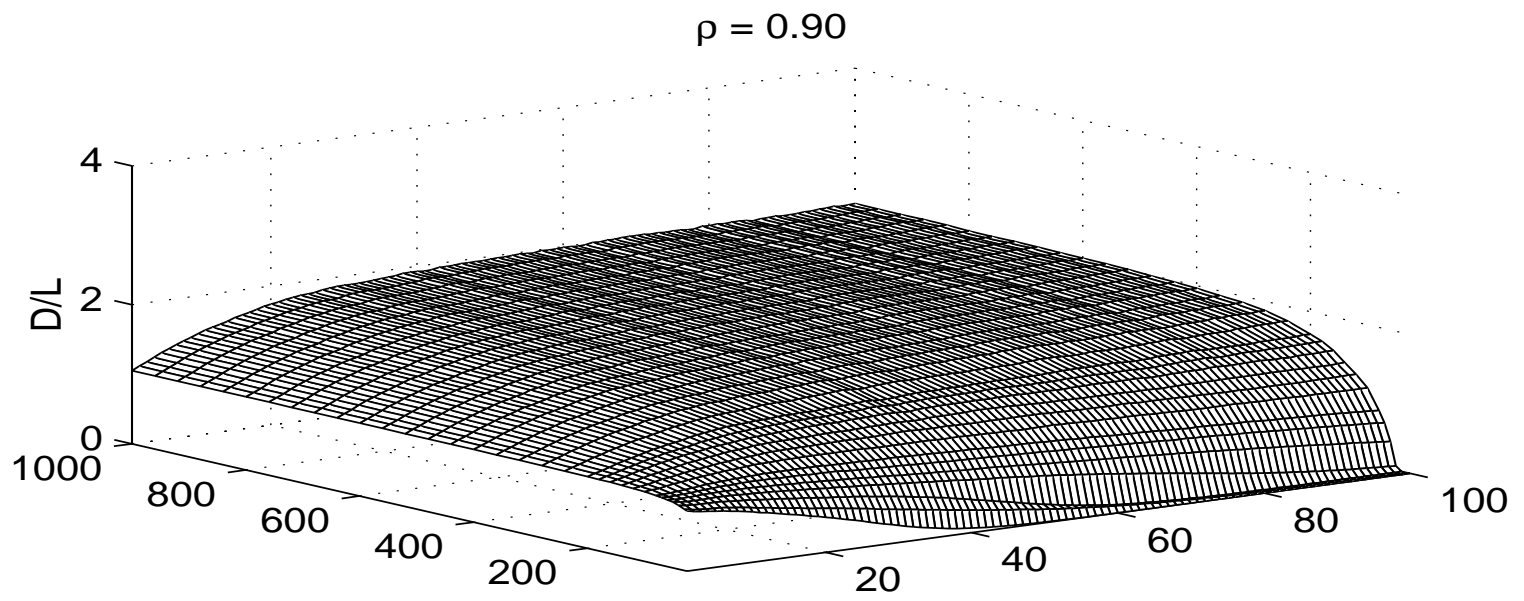

Sample Size

Forecast Horizon

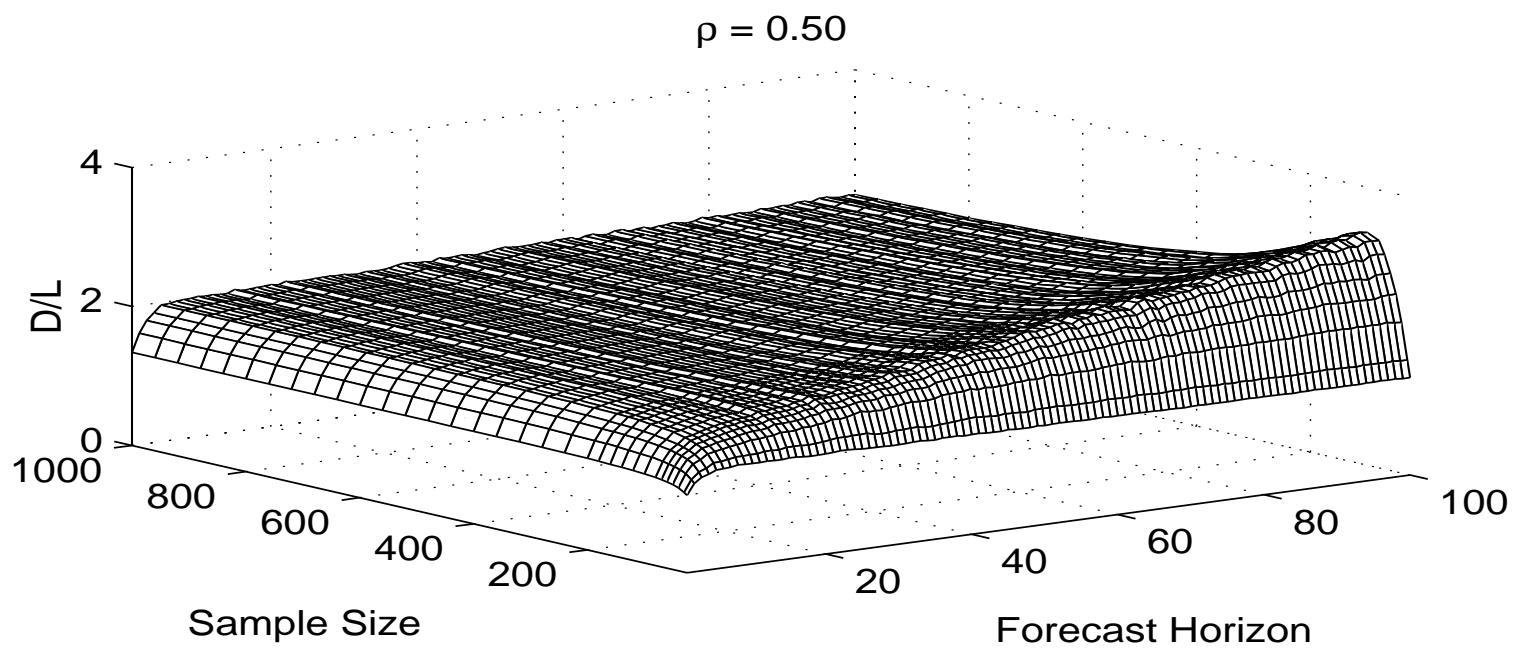

SOURCE: $\quad 20,000$ Monte Carlo trials based on DGP $y_{t}=(a-a \rho+b \rho)+(b-b \rho) t+\rho y_{t-1}+\varepsilon_{t}$, where $\varepsilon_{t} \sim N\left(0,0.01^{2}\right), a=7.3707, b=0.0065$.

$\mathrm{D}$ denotes the model in first differences; $\mathrm{L}$ denotes the model in levels. 


\section{Figure 2a: PMSE(D)/PMSE(P)}

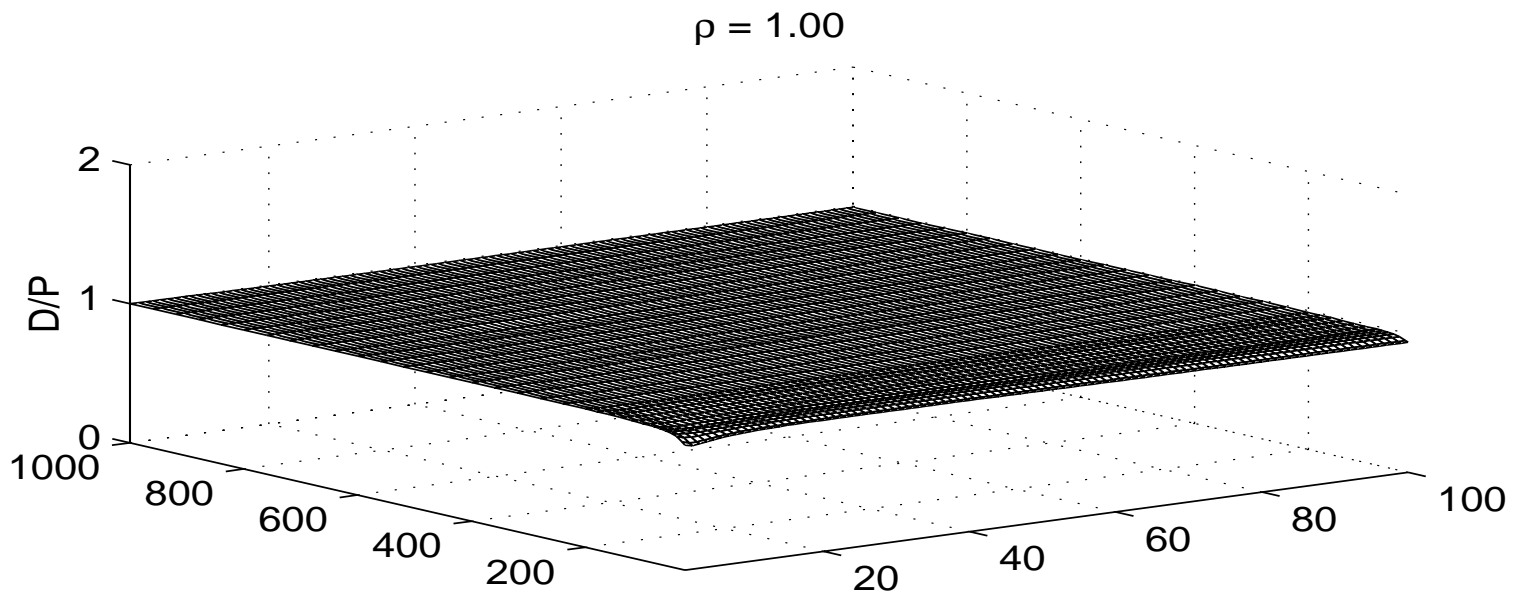

Sample Size

Forecast Horizon

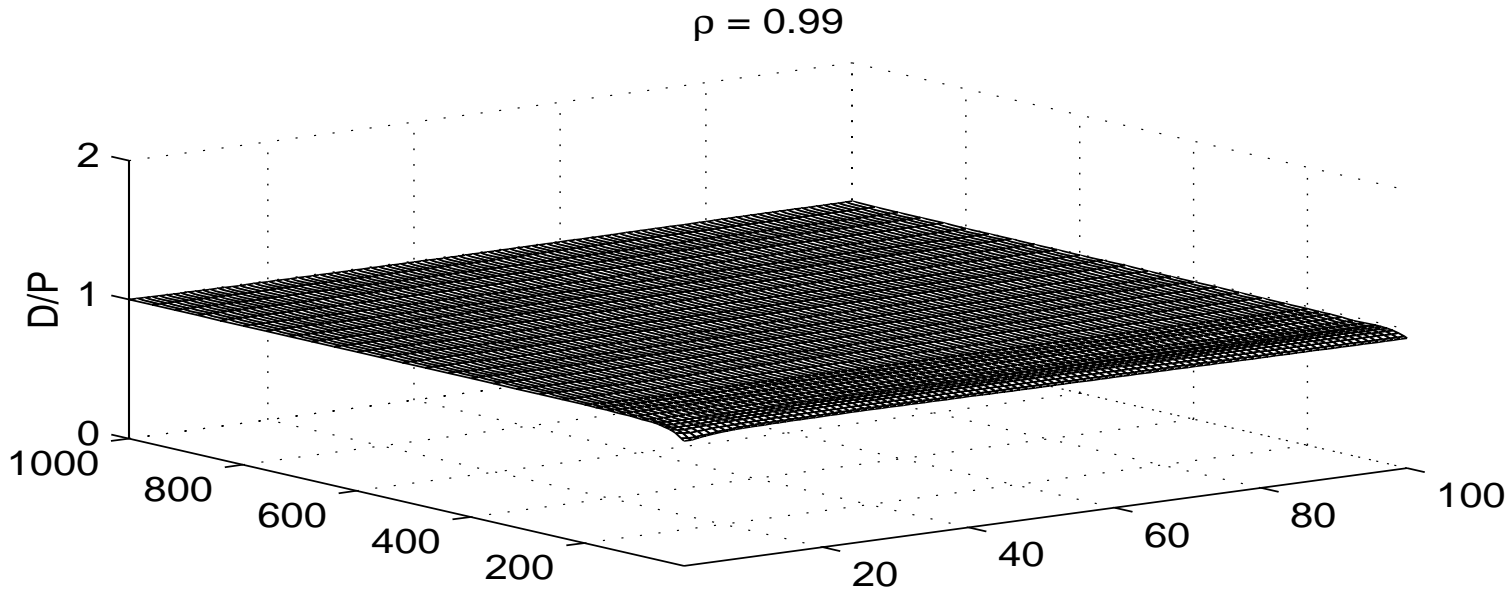

Sample Size

Forecast Horizon

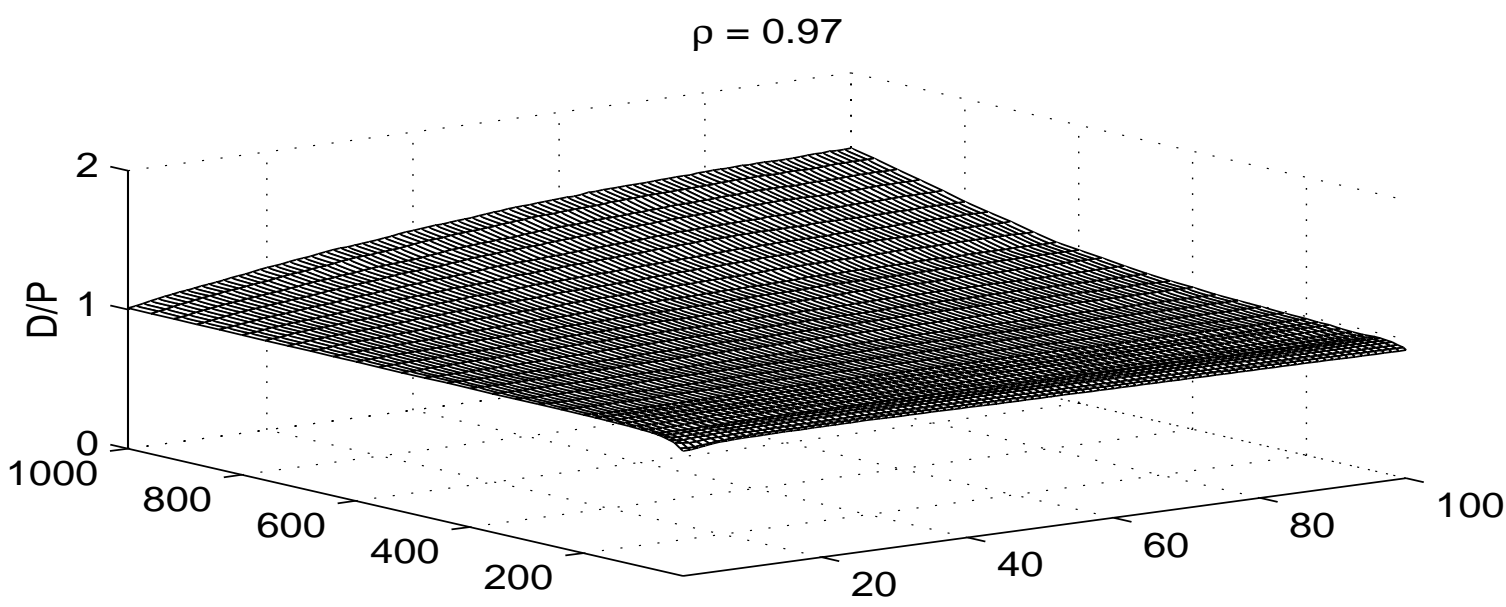

Sample Size

Forecast Horizon

SOURCE: $\quad 20,000$ Monte Carlo trials based on DGP $y_{t}=(a-a \rho+b \rho)+(b-b \rho) t+\rho y_{t-1}+\varepsilon_{t}$, where $\varepsilon_{t} \sim N\left(0,0.01^{2}\right), a=7.3707, b=0.0065$.

$\mathrm{D}$ denotes the model in first differences; $\mathrm{P}$ denotes the model after pre-testing. 


\section{Figure 2b: PMSE(D)/PMSE(P)}

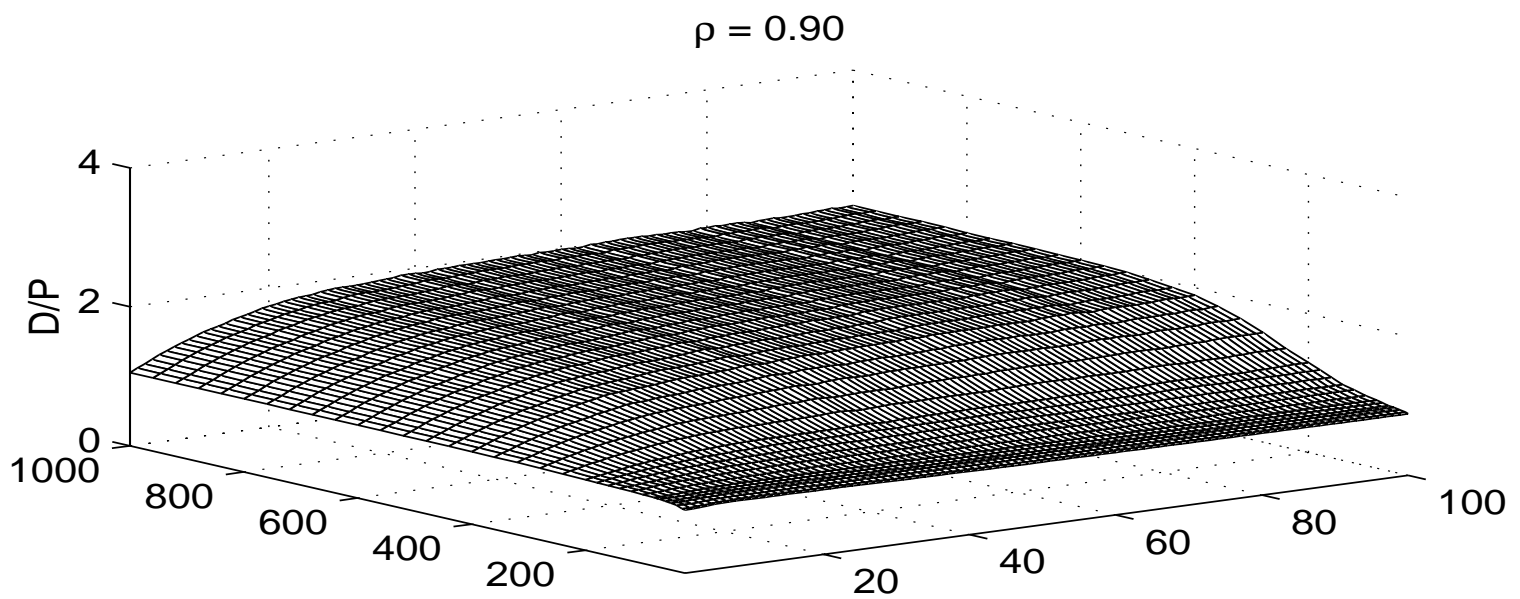

Sample Size

Forecast Horizon

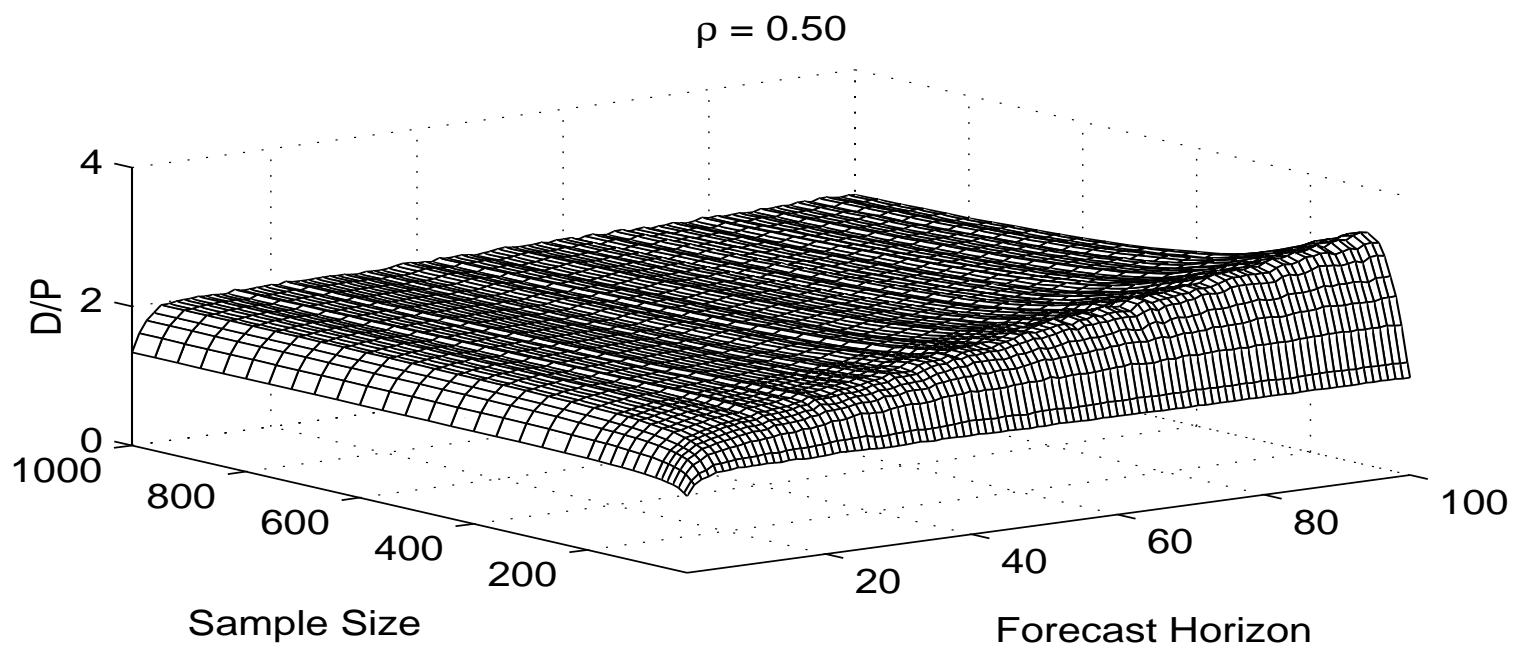

SOURCE: $\quad 20,000$ Monte Carlo trials based on DGP $y_{t}=(a-a \rho+b \rho)+(b-b \rho) t+\rho y_{t-1}+\varepsilon_{t}$, where $\varepsilon_{t} \sim N\left(0,0.01^{2}\right), a=7.3707, b=0.0065$.

$\mathrm{D}$ denotes the model in first differences; $\mathrm{P}$ denotes the model after pre-testing. 


\section{Figure 3a: PMSE(P)/PMSE(L)}

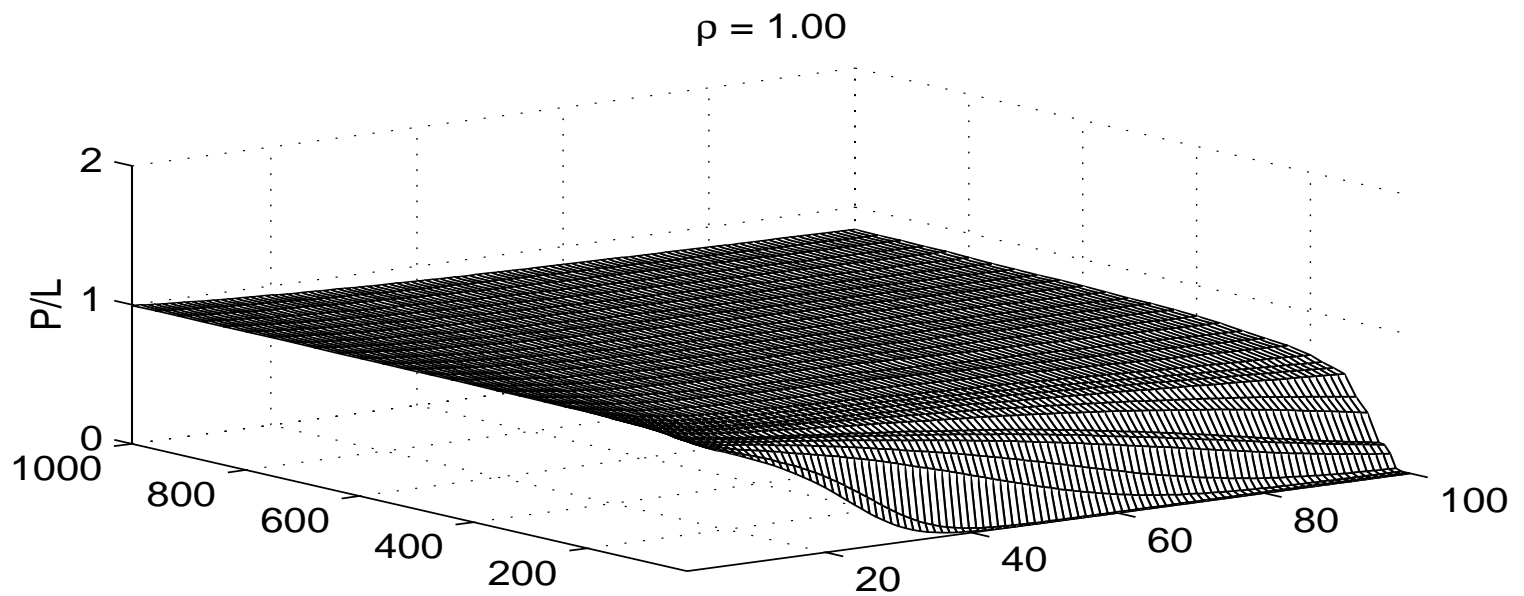

Sample Size

Forecast Horizon

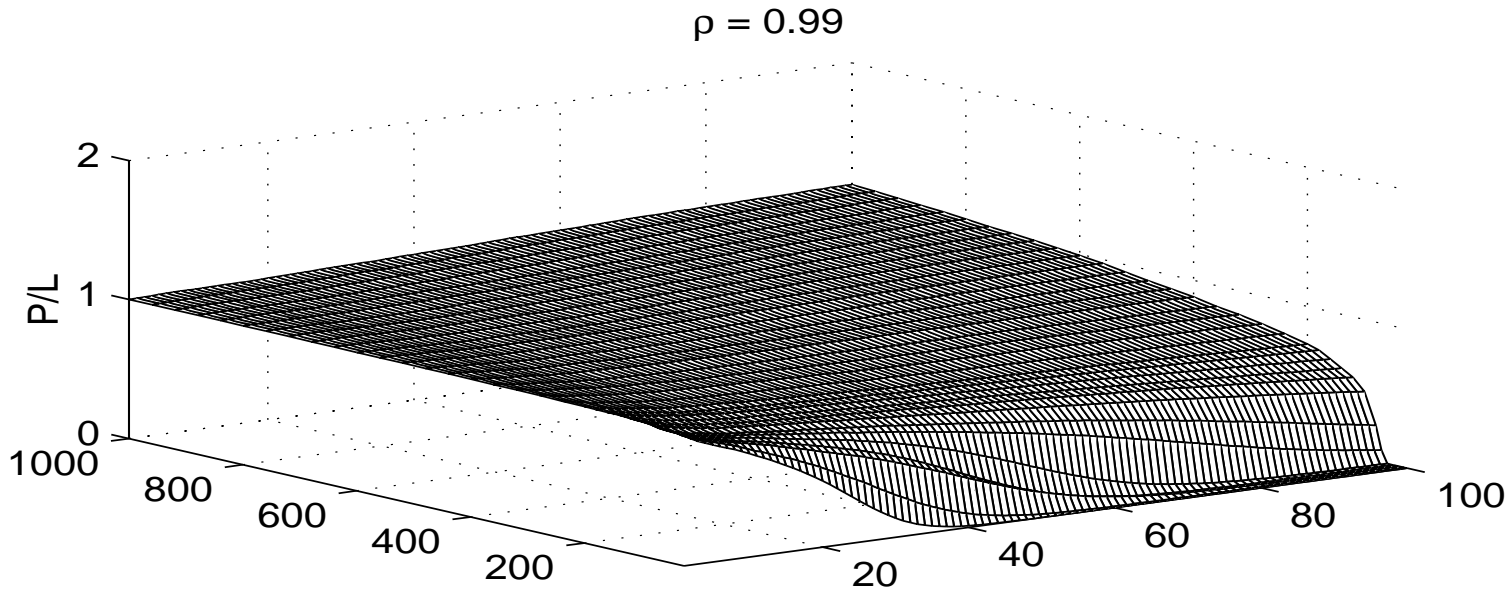

Sample Size

Forecast Horizon

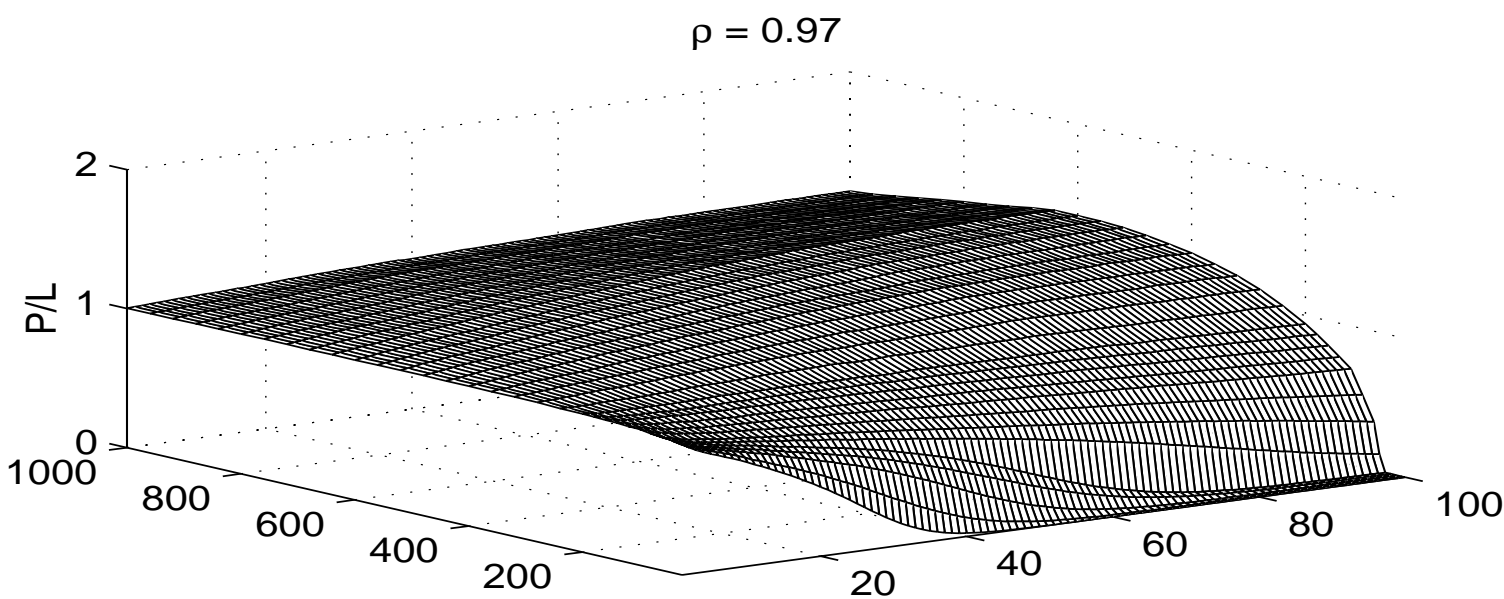

Sample Size

Forecast Horizon

SOURCE: $\quad 20,000$ Monte Carlo trials based on DGP $y_{t}=(a-a \rho+b \rho)+(b-b \rho) t+\rho y_{t-1}+\varepsilon_{t}$, where $\varepsilon_{t} \sim N\left(0,0.01^{2}\right), a=7.3707, b=0.0065$.

$\mathrm{P}$ denotes the model after pre-testing; $\mathrm{L}$ denotes the model in levels. 


\section{Figure 3b: PMSE(P)/PMSE(L)}

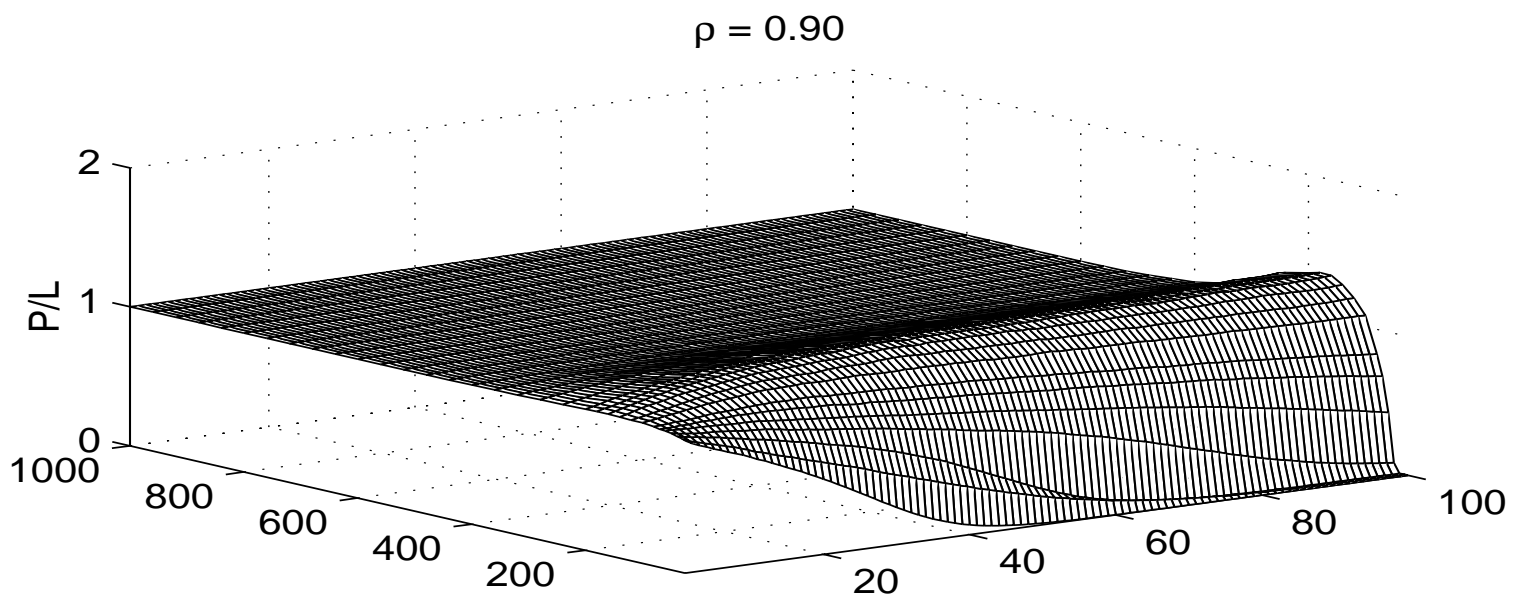

Sample Size

Forecast Horizon

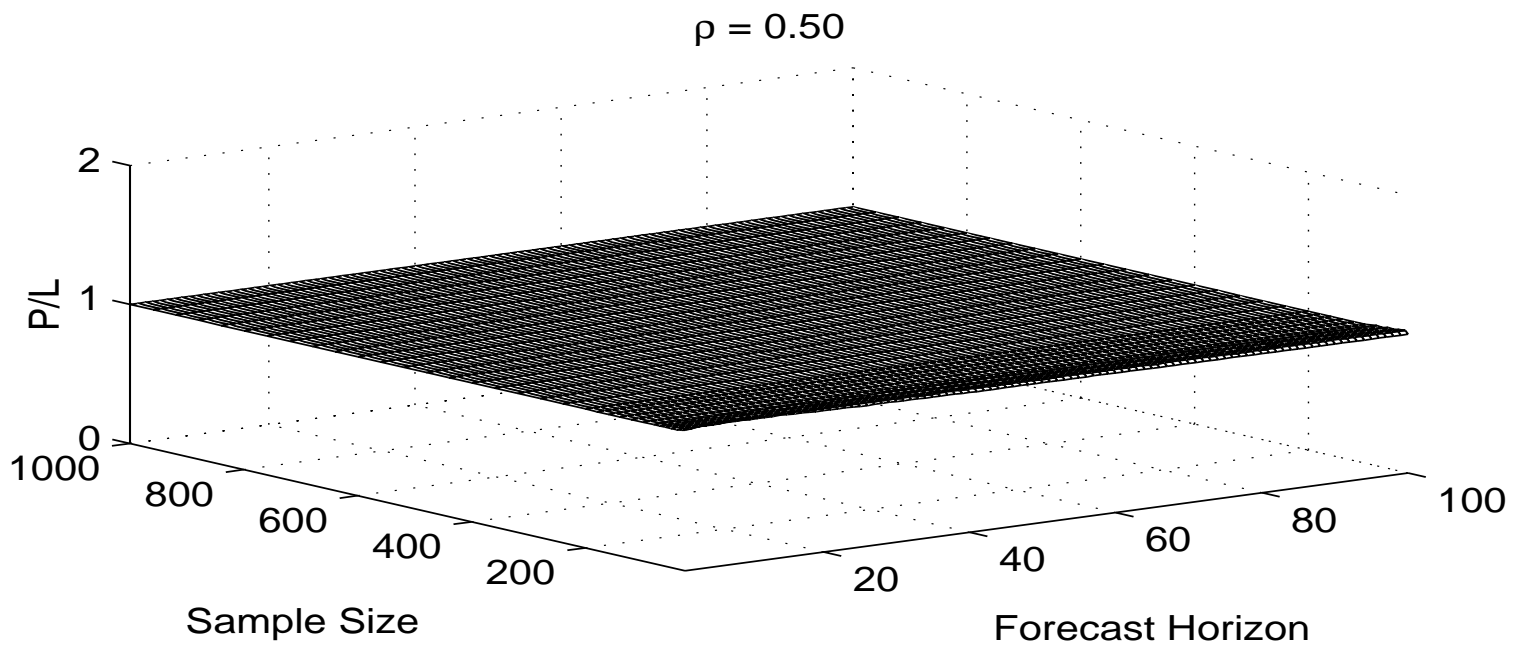

SOURCE: $\quad 20,000$ Monte Carlo trials based on DGP $y_{t}=(a-a \rho+b \rho)+(b-b \rho) t+\rho y_{t-1}+\varepsilon_{t}$, where $\varepsilon_{t} \sim N\left(0,0.01^{2}\right), a=7.3707, b=0.0065$.

$\mathrm{P}$ denotes the model after pre-testing; $\mathrm{L}$ denotes the model in levels. 


